\title{
PELATIHAN PARENTING POLA ASUH PADA ORANG TUA ASUH DI RUMAH YATIM YMAJU TALANG BAKUNG JAMBI
}

DOI: https://doi.org/10.33024/jkpm.v4i5.4825

\author{
Ani Astuti ${ }^{1}$, Mefrie Puspita ${ }^{2}$, Diah Merdekawati ${ }^{3 *}$ \\ 1-3 Program Studi Ilmu Keperawatan \\ Sekolah Tinggi Ilmu Kesehatan Harapan Ibu Jambi
}

Disubmit: 18 Agustus 2021 Diterima: 03 September 2021

Diterbitkan: 03 Oktober 2021

Email korespondensi: zelvyeliva@gmail.com

\begin{abstract}
ABSTRAK
Orang tua merupakan pihak yang bertanggung jawab atas terbentuknya karakter anak. Pola asuh yang diberikan dan diterapkan berpengaruh untuk masa depan anak. Untuk menjadi orang tua asuh merupakan suatu tantangan, karena memerlukan kesabaran dan keikhlasan. Agar tidak salah dalam menerapkan pola asuh, penting bagi orang tua asuh untuk mengetahui macam-macam pola asuh. Tujuan pelatihan parenting ini adalah untuk meningkatkan pengetahuan orang tua asuh tentang pola asuh yang dapat diterapkan pada anak asuh di Rumah Yatim YMAJU Talang Bakung Jambi. Kegiatan yang dilakukan pada pelatihan berupa pemberian materi, tanya jawab, diskusi kelompok dan dilakukan pemutaran video terkait pola asuh. Selain itu, untuk menyalurkan kreativitas anak, disediakan fasilitas bermain dan mini pustaka. Terdapat peningkatan pengetahuan peserta tentang pola asuh setelah diberikan pelatihan parenting serta sebagian besar anak bermain pada taman bermain dan mengunjungi mini pustaka.
\end{abstract}

Kata Kunci: Pelatihan parenting, pola asuh, taman bermain, mini pustaka

\begin{abstract}
Parents are responsible for the formation of children's character. The parenting style that is given and applied affects the future of the child. Becoming a foster parent is a challenge because it requires patience and sincerity. In order not to be wrong in applying to parents, foster parents need to know the various parenting patterns. The purpose of this parenting training is to increase the knowledge of foster parents about parenting that can be applied to foster children at YMAJU Yatim House Talang Bakung Jambi. Activities carried out in the training included providing material, question and answer, group discussions, and video screenings related to parenting. In addition, to channel children's creativity, play facilities and mini-libraries are provided. There was an increase in participants' knowledge about parenting after being given parenting training and most of the children played on the playground and visited the mini library.
\end{abstract}

Keywords: Parenting training, parenting, playground, mini library 


\section{PENDAHULUAN}

Anak-anak adalah generasi penerus bangsa yang ditangannya lah nanti pengelolaan bangsa ini dititipkan Mereka akan berkembang menjadi pribadi yang bermoral, berakhlak dan berkarakter kuat serta tangguh bergantung pada bagaimana pola asuh yang mereka terima sejak mereka dilahirkan. Namun banyak sekali anak-anak yang kurang beruntung karena harus kehilangan tulang punggung keluarga saat usia mereka masih sangat belia. Mereka harus tinggal dengan sanak famili yang juga mempunyai anak yang harus diasuhnya. Bahkan anak terkadang harus dititipkan dipanti asuhan karena tidak ada sanak famili yang merawat dan membesarkan mereka. Hal ini tentu suatu hal yang dapat mengguncang jiwa anak, tidak ada lagi tempat panutan, tempat mendapatkan kehangatan dan kasih sayang dari orag tua.

Menurut Sjarkawi (2011) keluarga terutama orang tua dan saudara mempunyai peran yang sangat besar dalam terbentuknya kepribadian dan karakter anak. Karakter anak akan terbentuk sesuai dengan pola asuh yang diterima sejak lahir. Selain itu menurut Desmita (2012) aspek yang sangat penting dalam hubungan orang tua dan anak adalah bagaimana orang tua menerapkan pola asuhnya pada anak, tipe pola asuh yang dilakukan orang tua pada anak mempunyai pengaruh pada perkembangan jiwa anak, karena dari keluarga lah pertama anak mendapatkan bimbingan dan pendidikan.

Rumah Yatim Mutiara Abadi Amal Jariah Umat (YMAJU) merupakan Yayasan yang bergerak dalam bidang pembinaan anak-anak yatim dan dhuafa yang ada di RT 17 Kel. Eka Jaya dan sekitarnya. Panti Asuhan ini berdiri pada tahun 2016 dengan dilatar belakangi oleh banyaknya jumlah anak yatim, yatim piatu dan dhuafa ynag berdomisili di daerah tersebut. Anak yatim dan dhuafa didaerah tersebut memiliki taraf kehidupan dan ekonomi yang cukup memperihatinkan. Yatim dan dhuafa yang tidak memiliki tempat tinggal ditampung di panti YMAJU, namun anak-anak yang masih punya keluarga dan sanak famili masih tinggal bersama-sama keluarga mereka. Jumlah anak yatim dan dhuafa yang dibawah binaan Panti Asuhan YMAJU berjumlah 81 orang dengan berbagai tingkat usia.

YMAJU memiliki berbagai program dalam mensejahteraan anak yatim dan dhuafa, diantaranya pengajian rutin, kelas Bahasa Inggris dan forum diskusi yang diadakah setiap minggunya. Namun YMAJU belum melihat secara khusus bagaimana perkembangan kepribadaian anak dengan pola asuh yang diterapkan di Rumah Yatim dan juga anak yatim yang dititipkan dengan keluarga mereka. Selain itu terbatasnya sarana dan prasarana edukatif yang ada di Rumah Yatim terutama yang berhubungan dengan stimulus untuk perkembangan anak juga merupakan kendala yang dihadapi oleh YMAJU.

Dengan adanya PKM di Rumah Yatim YMAJU kota Jambi ini akan dilakukan upaya peningkatan pemberdayaan dan pengelolaan panti asuhan ini dengan cara dilakukannya pelatihan dan pendampingan tentang parenting yang bertujuan untuk meningkatkan pengetahun dan kemampuan ibu asuh dalam menerapkan pola asuh, menyediakan sarana edukatif taman bermain anak dan mini perpustakaan. 


\section{MASALAH}

Adapun masalah pada Rumah Yatim YMAJU ini adalah kurangnya pengetahuan tentang penerapan pola asuh pada anak-anak dan tidak adanya prasarana bermain dan edukatif yang diperlukan oleh anak-anak.

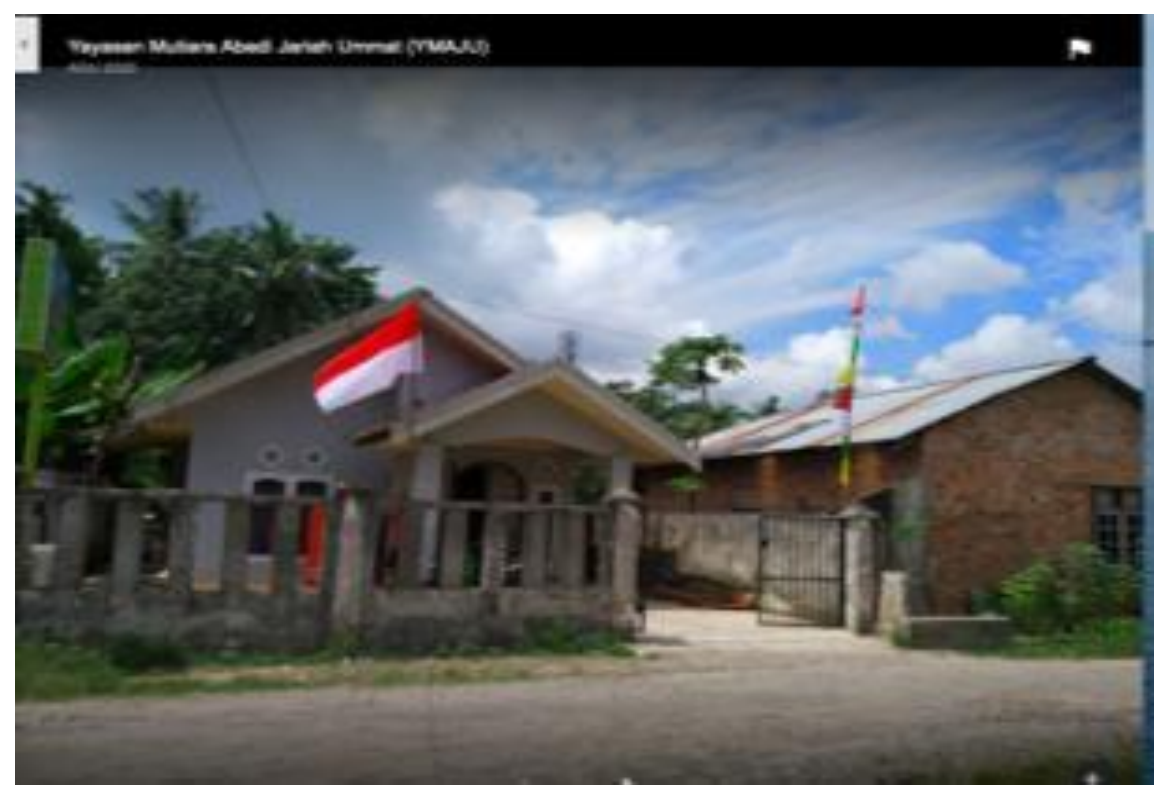

Gambar 2.1 Rumah Yatim YMAJU

\section{METODE}

Adapun yang peserta yang akan mengikuti kegiatan ini sebanyak 25 orang ibu asuh yang memiliki 80 anak asuh.

a. Tahap Persiapan

Pada tahap ini dilakukan indentifikasi permasalahan yang dihadapi mitra dengan cara observasi lapangan dan wawancara langsung dengan mitra, selanjutnya membuat sepakatan dengan mitra dengan penandatanganan kontrak kerjasama. Pada tahap ini juga dilakukan penjajakan kepada nara sumber yang akan ikut serta berperan dalam kegiatan pengabdian ini yaitu narasumber dari psikolog anak. Selain itu dilakukan pemetaan dana terhadap pembiayaan yang akan dikeluarkan selama kegiatan dilakukan. Selain itu juga pada tahap ini dibuat rancangan dan jadwal kegiatan yang akan dilakukan.

b. Tahap pelaksanaan

Pada tahap ini dilakukan sejumlah kegiatan yang sudah dirancang pada tahap persiapan sesuai dengan jadwal yang telah dibuat. Pada tahap awal pelaksanaan dilakukan pelatihan tentang parenting: penerapan pola asuh yang baik pada anak, pelatihan ini dilakukan selama 2 hari berupa penyampaian materi dan diskusi

Kegiatan selanjutnya pada tahap pelaksanaan ini adalah pengadaan sarana dan prasarana edukatif seperti taman bermain dan mini perpustkaaan untuk menunjang kemampuan kognitif dan meningkatkan minat baca anak.

c. Tahap monitoring

Pada tahap ini dilakukan monitoring dan pendampingan terhadap kegiatan yang telah dilakukan pada tahap pelaksaan. Adapun yang dilakukan monitoring dan pendampingan adalah bagaimana pelaksanaan parenting: 
pola asuh yang baik bagi anak panti. Selama tahap monitoring dinilai bagaimana kesiapan dan kemajuan yang telah dicapai oleh para ibu pengasuh.

d. Tahap evaluasi

Pada tahap ini dilakukan evaluasi terhadap semua kegiatan yang telah dilakukan dari tahap persiapan sampai dengan tahap monitoring. Tahap ini menilai apa yang telah dicapai dan yang belum tercapi dan kendala yang di temukan selama kegiatan berlangsung untuk kemudian dibuat rencana tindaklanjutnya. Pada tahap ini juga dilakukan evaluasi terhadap luaran yang telah ditargetkan.

e. Pelaporan

Pada tahap ini dilakukan penulisan laporan kegiatan yang telah terlaksana, mulai dari tahap persiapan sampai dengan tahap evaluasi. Pelaporan ini selanjutkan akan dilaporkan ke bagian simlitabmas dikti.

\section{HASIL DAN PEMBAHASAN}

Kegiatan parenting dilakukan pada tanggal 24-25 Juli 2021. Adapun peserta yang dapat mengikuti kegiatan ini sebanyak 25 orang ibu asuh. Langkah-langkah kegiatan di awali dengan pengisian kuesioner pemahaman tentang pola asuh, pemberian materi oleh psikolog anak, penayangan video contoh parenting, tanya jawab, diskusi kelompok dan evaluasi pengetahuan peserta serta ditutup dengan pengisian kuesioner pemahaman tentang pola asuh.

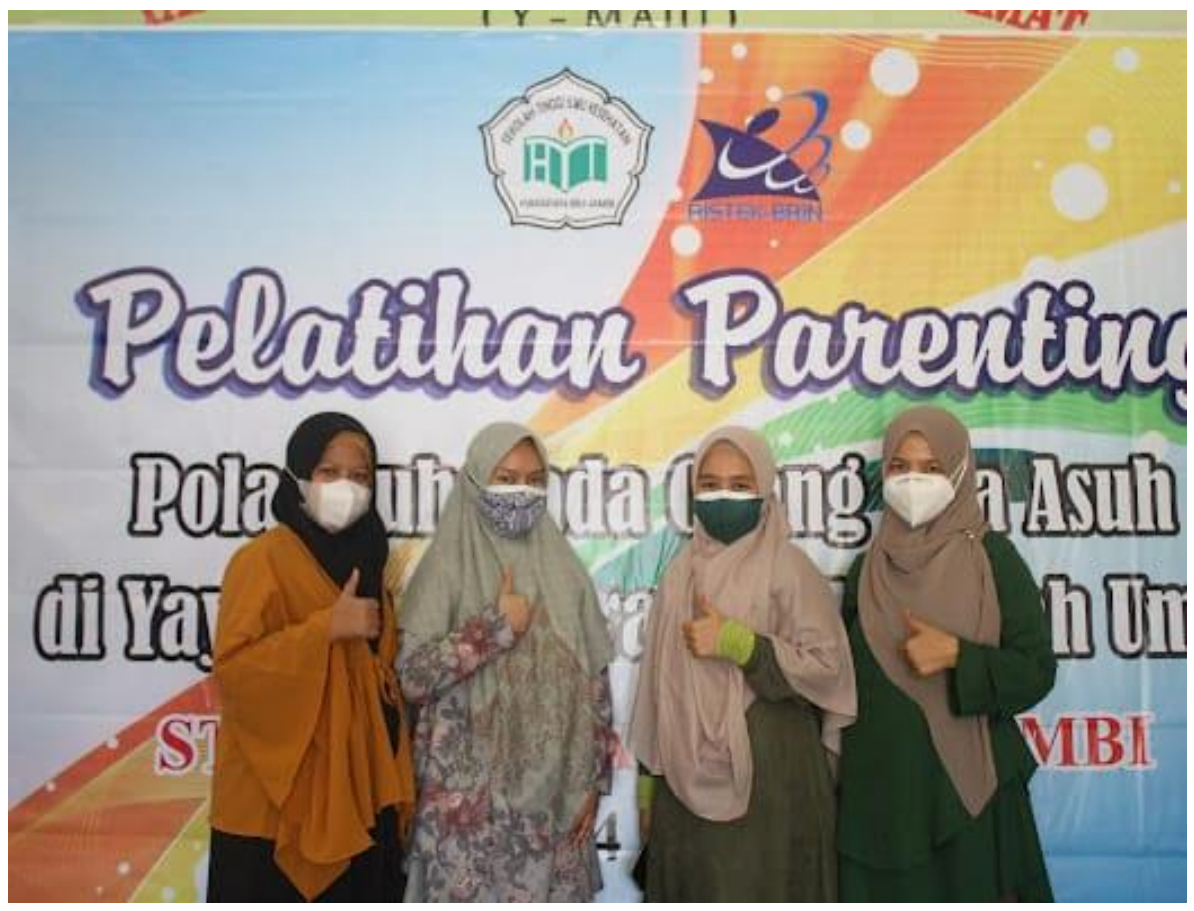

Gambar 4.1 Tim PKM bersama Narasumber Pelatihan Parenting 


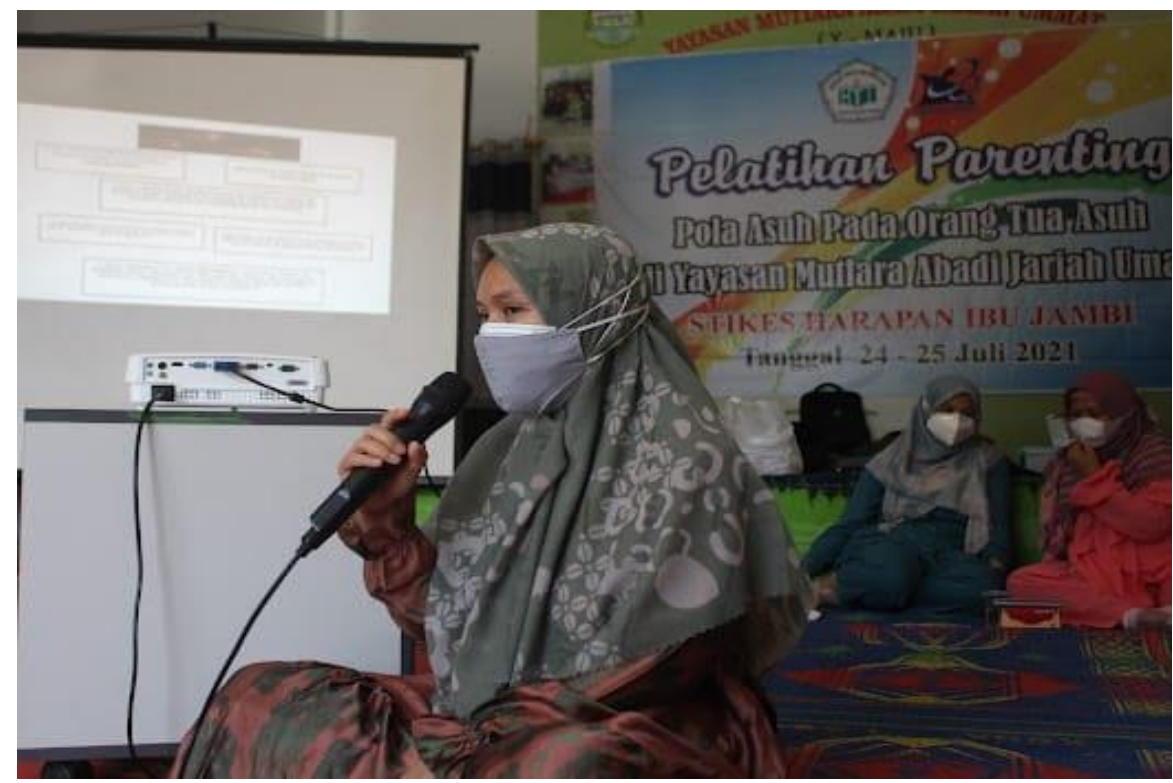

Gambar 4.2 Penyampaian Materi dalam Pelatihan Parenting

Hasil evaluasi pada kegiatan pelatihan parenting diketahui bahwa pengetahuan peserta meningkat serta $100 \%$ peserta berperan aktif dalam kegiatan. Peserta terlihat antusias dalam mengikuti kegiatan pelatihan yang dibuktikan dengan sesi tanya jawab yang berlangsung sangat baik. Melalui pelaihan parenting, peserta mengetahui pola asuh yang dapat diterapkan pada anak asuh.

Pola asuh merupakan dasar untuk membentuk kepribadian anak, dimana pola asuh yang baik akan menentukan bagaimana karakter anak dimasa yang akan datang. Orang tua adalah ujung tombak dalam pembentukan karakter anak, bagaimana prilaku anak dan perkembangan kepribadiannya tergantung dari pola asuh yang diterapkan orang tua mulai dari anak lahir sampai anak beranjak dewasa. Keluarga menjadi tempat awal bagi anak memperoleh pendidikan karena orang tua adalah pendidik kodrati bagi anak.

Pengasuh utama anak adalah orang tua yang memiliki kontribusi besar dalam memberikan cinta dan perhatian besar pada anak yang sangat berpengaruh pada perkembangan kepribadian anak (Santrock, 2011). Pola asuh yang diterapkan orang tua sangat berpengaruh pada kreatifitas anak. Cara orang tua mengasuh dan sikap orang tua memberikan Pendidikan pada anak juga sangat berperan pada perkembangan mental anak. Penelitian yang dilakukan Mefrie (2018) menunjukkan bahwa pola asuh yang diterapkan orang tua dalam mengasuh anak berpengaruh terhadap kreatifitas anak. 


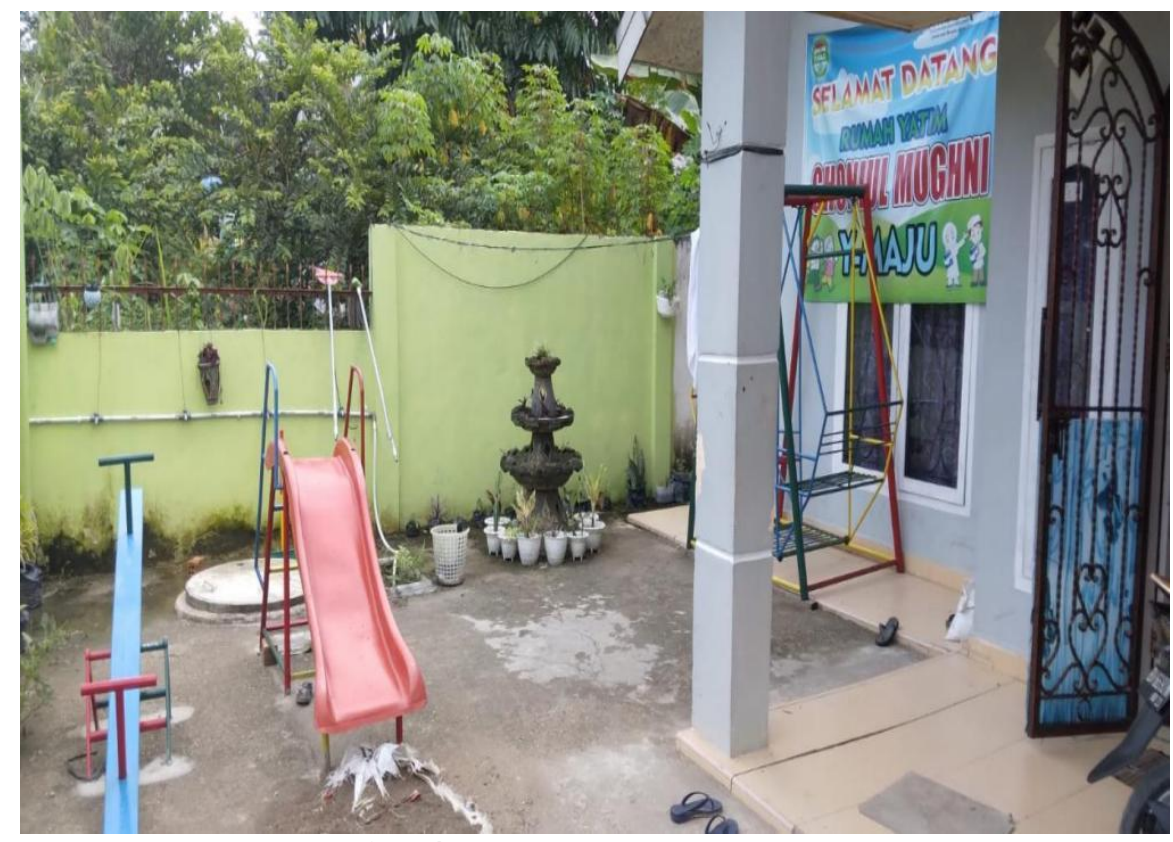

Gambar 4.5 Taman Bermain

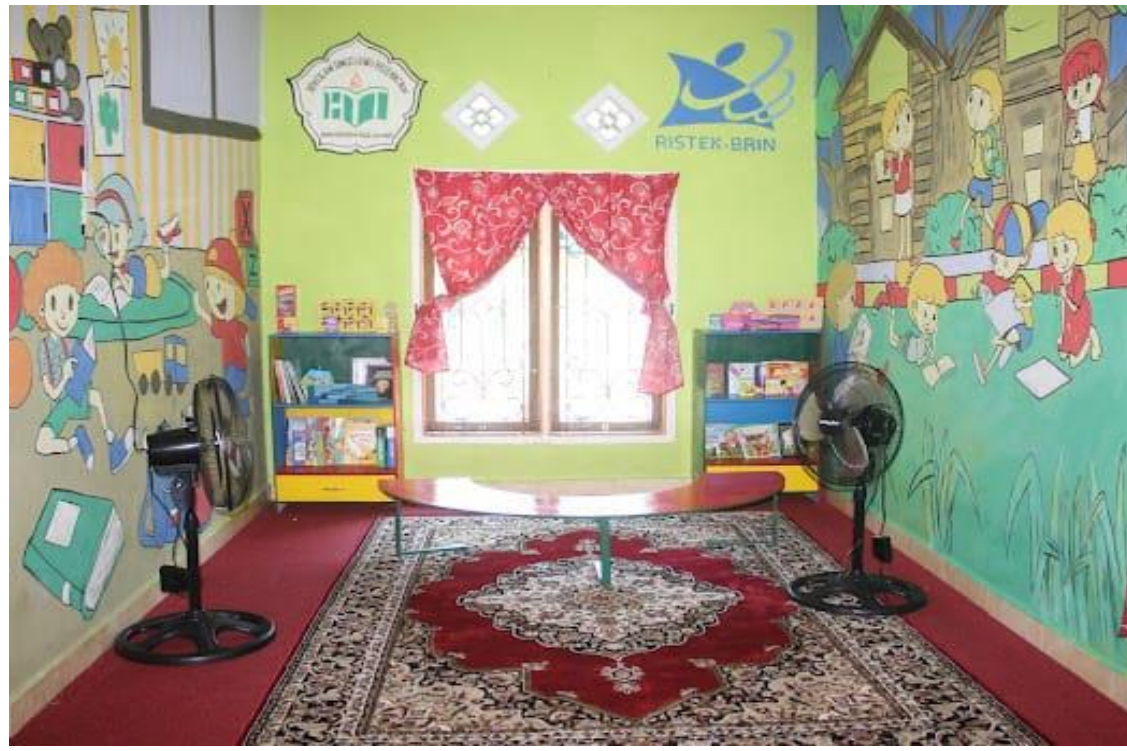

Gambar 4.6 Mini Pustaka

Hasil evaluasi tampak bahwa anak-anak ceria bermain di taman bermain. Selain itu, mulai munculnya minat anak dalam membaca melalui mini pustaka yang disediakan. Anak-anak menghabiskan waktu luang bersama teman baik di taman bermain, maupun di mini pustaka. Ibu asuh Rumah Yatim YMAJU mengatakan tidak merasa kesulitan lagi untuk mencari anak-anak yang bermain jauh dari Rumah Yatim dikarenakan anak-anak menggunakan fasilitas yang telah disediakan.

Mengasuh anak bukan lah sesuatu yang sepele, mengasuh adalah hal yang sangat kompleks, apalagi di panti asuhan dimana satu ibu pengasuh harus mengasuh banyak anak. Diperlukan sarana dan prasarana bermain untuk merangsang kreatifitas anak dan mengalihkan anak dari sikap ketergantungan pada orang tua asuh. Sarana bermain dapat menjadi stimulus dalam 
berkembangan anak, menurut Suyadi (2012) bermain dapat merangsang perkembangan kogitif anak. Untuk itu diperlukan pengadaan sarana bermain seperti taman bermain dan mini perpustakaan untuk meningkatkan minat baca dan kreatifitas anak. Penelitian Gusmao et al (20016), menyatakan bahwa kegiatan dan keinginan anak untuk bermain di taman bermain dengan kategori tinggi.

\section{KESIMPULAN}

Kepribadian dan kecerdasan anak dibentuk dari keluarga berdasarkan pola asuh yang diterapkan, khususnya pada anak asuh. Agar tidak keliru dalam menerapkan pola asuh, hendaknya orang tua asuh lebih memahami dan menerapkan pola asuh sesuai dengan yang dibutuhkan anak.

Pelatihan parenting merupakan wadah yang tepat bagi orang tua asuh untuk mengenal lebih dekat tentang pola asuh. Melalui pelatihan parenting, pengetahuan peserta dapat meningkat. Selain itu, anak dapat meningkatkan kreativitas serta pengetahuannya melalui fasilitas bermain dan mini pustaka.

\section{DAFTAR PUSTAKA}

Desmita. (2012). Psikologi Perkembangan Peserta Didik. Bandung: Remaja Rodakarya.

Gusmao et al. (2016). Ketersediaan Ruang Bermain Anak di Kelurahan Baranangsiang, Kecamatan Bogor Timur. Bogor: Program Studi Perencanaan Wilayah dan Kota Fakultas Teknik Unpak.

Mefrie P, Sutinah, Maria U,. (2018) Pengasuhan orang tua dengan kreativitas anak prasekolah di TK Al-Azhar Kota Jambi, Riset Informasi Kesehatan, Vol. 7, No. 2.

Santrock. (2011). Perkembangan Anak. Jakarta: Erlangga.

Sjarkawi. (2011). Pembentukan Kepribadian Anak Peran Moral, Intelektual, Emosional dan Sosial sebagai Wujud Integrasi Membangun Jati Diri. Jakarta: Bumi Aksara.

Suyadi. (2014). Teori pembelajaran Anak Usia Dini: dalam kajian Neurosains. Bandung: PT Remaja Rosdakarya. 